\title{
Stategies for Equity \& Sustainability in Urban Transportation in Third World Mega-Cities
}

\author{
Rohinton Emmanuel
}

\begin{abstract}
The conventional approach to transportational problems has been building more and better highways. However, contrary to popular and academic expectations, more and better transportation technologies have led to an increase in time spent in transportation all over the world. In this paper we therefore propose mechanisms for equitable and sustainable transportation strategies, particularly for third world urban agglomerates. The solution proposed here is not an equitable distribution of more transport power, but a reduction in the need for it. It is argued that a ceiling on per capita energy use by means of design strategies for speed reduction is necessary to promote healthier urban transportation. Strategies for urban design alternatives that achieve this end are proposed.
\end{abstract}

\subsection{Introduction}

Urban transportation ills have long been recognized by planners and citizens alike. The conventional approach to transportational problems has been building more and better highways. Additionally, improvements to vehicular construction and performance are also suggested. However, it is plain to see that new roads are filled to capacity as soon as they are built, and improvements in vehicular performance is getting harder to achieve as vehicles are already highly mechanized.

Contrary to popular and academic expectations, more and better transportation technologies have led to an increase in time spent in transportation (Lowe, 1994). Better transportation has also led to larger and larger urban agglomerates, necessitating further transportation. Furthermore, urban decay, ill effects on the environment and quality of life also follow expansions in mechanized transport.

These concerns have led some countries (particularly in western Europe) to look for what is now euphemistically called "alternative transport choices." Encouragement of walking and cycling and greater subsidies to public transportation are some of the strategies typically grouped under such notions.

These conditions already exist in many third world cities, where walking, cycling and public transportation are the main stays of urban transportation (Wright, 1992). Yet, problems persist in these cities, and it is not unreasonable to argue that urban transportation is worse in mega cities of the third world. Obviously then, choice of modes alone is not going to solve the problem.

It is in this context that the current paper argues for equitable and sustainable transportation strategies, particularly for third world urban agglomerates. The hypothesis here is that urban transportation ills stem from an inequitable distribution of transportation power. Current urban planning and design practices aid in the perpetuation of such inequity. It is also argued that such a transportation paradigm is unsustainable for many third world cities.

The solution proposed here is not an equitable distribution of more transport power, but a reduction in the need for it. It is therefore argued that a ceiling on per capita energy use by means of design strategies for speed reduction is necessary to promote healthier urban transportation. Strategies for urban design alternatives that achieve this end are proposed.

A concern with urban transport strategies for third world megacities is timely because the choices that foster mechanized transport are not yet fully made in these cities. While these cities are still in transition (from solely human powered transit to mechanized transport) now is perhaps the most opportune time to reverse the trend in favor of sustainable transport forms.

\subsection{Background.}

The early urban dwellers walked for the most part. Until the end of the $19^{\text {th }}$ century, this was the case in European, American and Australian cities (Manning, 1984). Cities were small enough to walk (less than 4 $\mathrm{km}$ in radius) and trips could be so arranged as to accomplish many tasks in one trip.

The growth in urban population and deteriorating conditions in central areas of cities lead to expansion of towns and faster modes to travel. Thus the first 
transition in urban transportation was from walking and other human-powered modes to public transport, usually powered by horses. The advent of electricity and subsequently the motorized transport lead to trams, buses, trains and other such mecahanized public transport modes. The peak in these faster public transport modes was reached in the early parts of the $20^{\text {th }}$ century.

However, public transport's heyday in many western cities came to an end with the advent of private motor car. The increase in car ownership in part was fueled by the desire to own a plot of one's own land, away from the hustle and bustle of cities. A boom in personal wealth brought automobiles within the reach of many. What is now known as the "urban sprawl," though not created by private motor car, was greatly fueled by it. For example, the advent of motorized public transit lead to an increase in Melbourne's city radius from 4 to $7 \mathrm{~km}$ while motor cars enabled the city to grow three-fold in just 60 years. This enlargement of the city also lead to a $50 \%$ drop in urban population density (Table 1). In the metropolitan area of Detroit, it is estimated that population will increase by about $6 \%$ in the next decade, but urban land area will expand by $40 \%$ (SEMCOG, 1991).

Table 1. Urbanization trends in Melbourne

Source: Manning, 1984: 69; Table 3.1

\begin{tabular}{|l|l|l|l|l|l|}
\hline Year & $\begin{array}{l}\text { Population } \\
\text { ('000) }\end{array}$ & $\begin{array}{l}\text { area } \\
\text { (sq. Km) }\end{array}$ & $\begin{array}{l}\text { Persons/ } \\
\text { Dwelling }\end{array}$ & $\begin{array}{l}\text { Density } \\
\text { (persons/ } \\
\text { sq. Km) }\end{array}$ & $\begin{array}{l}\text { City Radius } \\
\text { (Hypothetical) }\end{array}$ \\
\hline 1881 & 217 & 53 & 5.1 & 4,070 & 4.1 \\
\hline 1891 & 433 & 124 & 4.8 & 3,550 & 6.3 \\
\hline 1901 & 435 & 124 & 5.0 & 3,570 & 6.3 \\
\hline 1911 & 535 & 149 & 4.9 & 3,580 & 6.9 \\
\hline 1921 & 707 & 202 & 4.6 & 3,500 & 8.0 \\
\hline 1933 & 954 & 294 & 4.2 & 3,250 & 9.7 \\
\hline 1947 & 1,181 & 368 & 3.9 & 3,210 & 10.8 \\
\hline 1954 & 1,449 & 566 & 3.6 & 2,560 & 13.4 \\
\hline 1961 & 1.850 & 864 & 3.6 & 2.140 & 16.6 \\
\hline 1966 & 2,110 & 1,147 & 3.6 & 1,840 & 19.1 \\
\hline 1971 & 2,394 & 1,320 & 3.4 & 1,810 & 20.5 \\
\hline 1976 & 2,479 & 1,497 & 3.2 & 1,660 & 21.8 \\
\hline
\end{tabular}

Note: Hypothetical radius is calculated on the basis of the given population density equally distributed in a circular city on a boundless plain.

Very soon, motorized vehicles created their own distances which they alone could shrink. They "created such distances for all, but they could shrink them for only a few" (Illich, 1974). We characterize this disparity (distance to be covered vs. the distance possible to be covered for urban dwellers), as inequity in urban transportation.

These developments were certainly not the result of any ideological or commercial conspiracy. It is well to remember the appalling conditions of late $19^{\text {th }}$ and early $20^{\text {th }}$ century western cities from which these developments sprang. The unhealthy living conditions, greater densities of urban dwellers without access to public amenities, congestion, pollution and the lack of privacy contributed to a desire for open and airy cities where each can own a piece of land and still have access to a wide variety of activity choices. It was felt that faster and personalized transport modes would give urban dwellers access to such cities. Many architects and urban designers, including Le Corbusier and Frank Lloyd-Wright built up their ideal cities around cars that enable them to house large populations at lower densities, with activities concentrated in large-scale service centers. These idealists expected greater benefits from automobiles for all urban dwellers while retaining the advantages of urban living.

However, as more and more people began to have access to private motorized transport modes, the utility for all began to fall, and now has reached a point of dis-utility. Since benefits of speed is largely due to greater accessibility, increașes in population 
and concentration of activities in large-scale centers traded off these benefits (Manning, 1984). Thus, even after building extensive networks of highways and freeways, the first world cities are unable to solve their congestion problems. The situation is no better in third world cities that have not yet fully automated their urban transport.

\subsection{Public Cost of Motorized Urban Transport}

The early public transport based on horse-pulled carriages and trams, later motorized, recovered their costs mainly by fares and tolls collected from the passengers. Although it is debatable as to whether the toll was sufficient for road construction and maintenance, the social costs were minimal.

However, it is not so with fast modes of transport, both private and public. Manning (1984) listed five possible social costs that are typically un/underpaid by motorists:

1. The costs of road construction and maintenance

2. Collision costs

3. Environmental costs

4. Subsidies to fossil fuels

5. Cost to those not owning or have access to motor vehicles (Manning, 1984: 100).

\subsubsection{Cost of Motorways}

While cost of labor, materials and inflation rates play important parts, the most significant factor in road construction costs, at least in the urban areas, is the value of land. Manning (1984) estimated that up to $80 \%$ of urban road cost is tied to land costs. This can be a significant factor in high-density, third world cities where land prices are typically higher than firstworld cities (Gibbons, 1990).

The initial construction as well as maintenance cost of motorways are higher irrespective of whether users are "public" or "private." They are also equally expensive in both developed and developing countries. Thus, rail-road systems in urban Brazil costs US $\$ 20$ - 60 million $/ \mathrm{km}$ (in 1990 values) while a similar project in Canada also cost roughly the same amount (Wright, 1992).

Bus systems can be relatively cheaper, with the capital costs of buses being the largest item. However, in the urban third world, this too can be enormous, as these systems usually have to be imported, paying hard currencies.

The operational and maintenance costs of motorways, too are considerable. Wright (1992) found that in Brazil, upgrading an existing dilapidated roadway costs almost as much as a new roadway.

\subsubsection{Collision Costs}

In most countries, public expenses generated by traffic accidents are paid by taxpayers. The risk of personal injury or worse, is not equally distributed among all segments of the population. The risk of collision is also unequally distributed among motorized transport modes. Motorcycles pose the highest risk (Table 2).

Table 2. Death Rates for Some Motorized Transport in the United States

Source: Wright, 1992:104, Table 5

\begin{tabular}{|l|l|l|}
\hline Transport Modes & $\begin{array}{l}\text { Deaths per } \\
100 \text { million } \\
\text { passenger } \mathrm{km}\end{array}$ & $\begin{array}{l}\text { Risk relative to } \\
\text { transit bus }\end{array}$ \\
\hline Motor cycle & 25.5 & 4270.8 \\
\hline Passenger car & 0.600 & 100.6 \\
\hline Passenger train & 0.082 & 13.8 \\
\hline Scheduled airline & 0.048 & 8.0 \\
\hline Intercity bus & 0.044 & 4.6 \\
\hline Transit bus & 0.006 & 1.0 \\
\hline
\end{tabular}


Considering the smaller number of motorized vehicles in the third world, death rate per vehicle is higher in developing world. For example, Brazil, with almost half of US. population posted double the amount of accidental deaths caused by motor vehicles. More than two-thirds of the hospital beds in trauma and orthopedics in Brazil are occupied by accident victims (Wright, 1992: 89, quoting GEIPOT, 1987).

Buses are typically safer due to their size. Trains too, are safer because of their exclusive tracks and elaborate safety network. However, a single train accident can take disastrous proportion.

\subsubsection{Environmental Costs}

Transportation plays an important role in a country's energy consumption. Although the exact quantities vary from rich to poor countries, the pattern remain the same. Thus, while an industrialized country like U.S. spends $21 \%$ of its commercial energy consumption in transportation (Erley \& Mossena, 1980), a third world nation like Sri Lanka spends
$16.4 \%$ (Wijemanne, 1989). It is likely that the bulk of this transportation energy is spent in the urban sector.

Thermo-electric energy used by all mechanized modes of transport almost always waste a great portion of the energy. Only about $10.3 \%$ of energy produced at a power plant is actually used by an electric vehicle. A gasoline-powered car uses only about $7.1 \%$ of the energy delivered to its fuel tank (Salihi, 1973). If energy losses in mining and transporting of coal and crude oil are also included, these lower values could be reduced even further.

Within such lower energy conversion rates, motorized vehicles show a remarkable degree of variance. For example, an intercity bus in U.S. urban streets is more than 3 times more energy efficient (on the basis of passenger $\mathrm{km}$ traveled) than an automobile (Table 3). These differences result mainly from passenger capacities and not so much from energy-conversion technological differences between the modes:

Table 3. Energy Use by Passenger Vehicles in the U.S.A, 1985

Source: Wright, 1992: 49, Table 4

\begin{tabular}{|l|c|c|}
\hline Mode & $\begin{array}{l}\text { Load Factor } \\
\text { (passenger } \mathbf{~ k m ~ / ~} \\
\text { vehicle km) }\end{array}$ & $\begin{array}{c}\text { Relative Energy Use } \\
\text { (Intercity Bus = 1) }\end{array}$ \\
\hline Intercity Bus & 41.8 & 1.00 \\
\hline Intercity Rail & 19.1 & 2.12 \\
Commuter Rail & 35.6 & 2.19 \\
\hline Transit Bus & 12.7 & 2.43 \\
\hline Transit Rail & 23.1 & 2.77 \\
\hline Automobile & 1.7 & 3.20 \\
\hline Air - Certified Route & 89.3 & 3.82 \\
\hline
\end{tabular}

Note: passenger $\mathrm{km}=$ No. of Passengers $\times \mathrm{km}$ traveled; vehicle $\mathrm{km}=$ vehicle $\times \mathrm{km}$ traveled

Table 3 suggests that improvements in energy efficiency is possible if load factors can be increased. (Even a compact car carrying 4 passengers and doing $13 \mathrm{kmpl}$, generates a fuel efficiency of 52 passenger kilometre/itre which is higher than many city buses in U.S. cities). It is also possible to conclude that cities relying heavily on least energy officient modes (private automobiles) can be expected to waste more energy on the whole.

Wasted energy always leads to air pollution. And the air pollution trends in megaclites of the world are nothing but encouraging. In the mid-1980s, for example, the Global Environment Monitoring System (GEMS) network, linked to the United Nations Environment Program and the World Health Organization (WHO), had information on sulfur dioxide concentrations for 54 cities worldwide and half of these cities had pollution levels near to or exceeding the maxima WHO considered tolerable. For suspended particulate matter, 41 cities were monitored, and 37 had borderline or excessive levels (French 1990: 9-11).

The metropolitan area of Mexico City is an especially interesting case, since it may be both the world's 
most populous urban area and its most polluted (Wright, 1992). There, the shares in total emissions of transport vehicles and (in parentheses) some percentages for private cars are: 55 percent (31 percent) of nitrous oxides; 83 percent (48 percent) of hydrocarbons; 12 percent of sulfur dioxide; 12 percent of particulates; 98 percent ( 67 percent) of carbon monoxide; and 100 percent ( 80 percent) of lead (Quadri 1989: 13).

Transport-generated pollution in the form of ozone can be highly visible. Ozone is also known as smog and is not related to the ozone in the stratosphere, which protects the earth from excessive exposure to ultraviolet rays. Ozone is not emitted directly by vehicles; it is formed by subsequent complex reactions of sunlight with emissions of nitrous oxide (NOX), hydrocarbons (HC), and, to some extent, carbon monoxide (CO). Ozone is thus formed only in the presence of sunlight, especially intense sunlight.

Airborne pollutants are also one of the major causes of damage to buildings, historical monuments, home furnishings, clothing, vehicles, crops, forests, lakes, and water supplies. Some of this damage has been reasonably well publicized, such as the Black Forest in Germany, the Acropolis in Greece, the Taj Mahal in India and many ancient Italian and Egyptian monuments. However, the less publicized acidification of lakes and water supplies and damage to crops and other vegetation may already represent a major biological crisis. Half of Canada's eastern lakes are acid-sensitive and 150,000 of them suffer biological damage, while air pollution has reduced crop yields in countries as diverse as the United States and China (French 1990: 17-24).

\subsubsection{Subsidies to Fossil Fuels}

Fossil fuel remains heavily subsidized, not only in the west, but also in third world countries like Sri Lanka (Wijemanne, 1989). Oil prices which went up immediately following the two oil crises of the 70's (1973 and 1979), have remained low till recently, but are picking up again. Depending on the price fluctuations, poor countries and rich alike subsidize oil so that what motorists pay for use is only a fraction of the actual cost. The situation is the worst in non oil-producing developing nations which have to import crude oil using their meagre reserves of hard currencies.

\subsubsection{Cost to the Poor}

Even if all motorists pay their actual costs in terms of road construction, operation and maintenance, as well as pay their fair share of fuel taxes, there will still be a segment of the population unable or unwilling to drive. There are poor who cannot afford a vehicle, those with physical and mental handicap debarred from driving, minors, and those who chose not to drive. Ironically, motorized mode of transport that was supposed to bring freedom to all, has actually enslaved all to its dictates.

The case of inequity caused by such discrimination will be discussed later, but we must analyze the case of one car-owning households even in wealthy cities. Morris (1981) pointed out that the increase in one person car use for journey to work suggests that onecar households are effectively no-car households during the work-week. This is also reflected in the number of trips households make in chauffeuring non-driving members (Table 4).

Table 4. Annual Travel Distances by Car in U.S. Households Source: Lowe, M.D., 1994: 83, Table 5-1.

\begin{tabular}{|l|lc|c|}
\hline Purpose & \multicolumn{2}{|c|}{$\begin{array}{l}\text { Vehicle-km Per Household } \\
1969\end{array}$} & $\begin{array}{c}\% \text { Change } \\
1990\end{array}$ \\
\hline Work Commute & 6,730 & 7,808 & 1690 \\
\hline Shopping & 1,495 & 2,804 & 88 \\
\hline Personal & 2,043 & 4,850 & 137 \\
\hline Social \& Recreation & 6,587 & 6,533 & -1 \\
\hline TOTAL & 19,989 & 24,296 & 22 \\
\hline
\end{tabular}




\subsection{Inequity in Urban Transport}

To return to the fundamental contradiction with motorized urban transport, even if all the hidden costs are paid by motorists, mechanized transport discriminates against those who cannot afford to or don't want to drive, in three ways: Mechanized transport creates distances only it can cover: those who rely on non-mechanized modes are left out. Jobs follow mechanized modes, leaving those who cannot afford those modes chronically jobless. in poor countries not blessed with fossil-fuel, the social costs of importing as well as cleaning up the environmental - degradation left behind by the mechanized modes of transport are burdened on the non-user majority.

There is also the distinction of access vs. mobility: greater reliance on automobiles seems to have given more and more people greater and greater mobility, but that mobility comes at a price of greater distances to be covered (cf. Lowe, 1994).

\subsection{Unsustainabillty of Current Urban Transport Modes}

The social and environmental costs associated with increasing mecahnization of transportation, particularly urban transportation, is also unsustainable in the long term. As mentioned before, mecahanized transport requires large subsidies to build, operate and maintain which even the richer nations are finding difficult to achieve. The greater contribution of mechanized transport to air quality in urban areas is also a serious concern.

Unsustainability of mechanized urban transportation is amplified by the modal mix: higher dependence on low energy performers. will lead to unsustainable mechanized transport for the city. as a whole. Table 5 shows the relative energy use by passenger vehicles in the United States. Single passenger automobile dominated cities will have the most inefficient urban transportation system.

Table 5. Fuel Efficiency for U.S. Transport Vehicles Source: Wright, 1992, Table 6

\begin{tabular}{|l|c|c|}
\hline Mode & $\begin{array}{l}\text { Energy Use } \\
\text { Passenger kmpl }\end{array}$ & $\begin{array}{l}\text { Energy Use } \\
\text { Available Seats kmpl }\end{array}$ \\
\hline Intracity Bus & $32-110$ & 92 \\
\hline Intercity Train & $35-107$ & 190 \\
\hline Suburban Train & 85 & 170 \\
\hline Commuter Train & 43 & 85 \\
\hline Automobile & 11 & 51 \\
\hline Airplane & 06 & 29 \\
\hline
\end{tabular}

Note: A Passenger mile is transporting one passenger over one mile

Available seats mile is transporting $x$ number of seats over one mile

Greater reliance on mechanized modes of transport for urban traffic is also self-defeating in that these modes typically have lower urban passenger capacitles than human-powered modes like walking and cycling. A walkway can carry more than double the amount of people in cities than a thirty-seat bus: six times more than fully occupied cars running on wide streets (Table 6). 
Table 6. Transport Capacitles \& Average Speeds

Source: Wright, 1992

\begin{tabular}{|l|c|c|}
\hline Mode & $\begin{array}{l}\text { Capacity } \\
\text { (persons/meter/hr.) }\end{array}$ & $\begin{array}{c}\text { Speed } \\
\text { (kmph) }\end{array}$ \\
\hline Non-motorized modes & & \\
\hline Walkway & 3,609 & 3 \\
\hline Bikeway & 1,476 & 13 \\
\hline Mixed Traffic, City Street & & \\
\hline Cars with 4 Occupants & 381 & 24 \\
\hline Minibus (10 passengers) & 492 & 16 \\
\hline Bus (30 passengers) & 982 & 14 \\
\hline Expressway & & \\
\hline Cars with 4 Occupants & 2,362 & 64 \\
\hline Minibus (10 Passemgers) & 3,937 & 64 \\
\hline Bus (40 Passengers) & 6,562 & 64 \\
\hline High-Capacity Urban Rail & & \\
\hline Metro (22,500 pass./line hr.) & 5,577 & 34 \\
\hline Metro (40,000 pass./ line hr.) & 9,915 & 34 \\
\hline
\end{tabular}

Note: A wider street (13.4 m or wider) will increase the capacity for cars by about $10 \%$.

Cities with a combination of greater reliance on inefficient mode and lack of facilities for humanpowered modes, lead to energy inefficiency for the city as a whole. However, individual vehicles may achieve greater efficiencies. Newman \& Kenworthy (1988) showed this in a study conducted in Perth, Australia. As more and more people lived and travelled greater distances from the central city, the fuel use per capita increased though their vehicular kmpg's were improving. Technologies notwithstanding, a sprawling city will inevitably be energy-wasteful, and therefore unsustainable.

However, the pollution that comes from a greater reliance on mechanized mode of transportation, is not soley physical. Important as it may be, air pollution emanating from mechanized transportation can be controlled, though at a price. The greater evil seems a social one. Illich (1974) called it a "dependence on energy that brings about social inertia" (1974: 6).

"Even if non-polluting power were feasible and abundant, the use of energy on a massive scale acts on society like a drug that is physically harmless but psychically enslaving. A community can choose between ... maintaining its addiction or kicking it in painful cramps, but no society is at once autonomously active and hooked on progressively larger numbers of energy slaves" (1974: 6).

\subsection{Conventional Response to the Status Quo}

This section intends to show evidence for the impracticality of current models of urban transport planning, both in the orthodox paradigm of development (the "capitalist" mode) and the political economy paradigm (the "Social democracy" mode). In particular, it will be shown that these prevailing world views are incapable of approaching the real transportation issues in a third world city. The fundamental flaw in both world views is that they approach transportation as a mere economic activity. But the need to move about is not equal to transportation. This can be seen in both developed and the underdeveloped world: people opting for private modes of transport in the former and forced into "public" mode in the latter.

\section{Third World Urban Transportation in the Orthodox Paradigm of Development}

Advocates of purely privately-owned automobile based solutions to the transportation problems in the third world, can still be found in urban transportation 
literature. The solutions emanating from such auto apologists, to borrow a term used by Taebel and Cornehls (1977), include subsidized provision of automobile to all urban. dwellers, and the development of more affordable, energy-efficient vehicles. It must however be mentioned that such views are relatively rare.

Apart from the minuscule apologists, one can detect three groups of responses to the problem of third world urban transportation within the orthodox paradigm: status quo, balance, and basic needs approach. Thomson (1983) typifies the first viewpoint.

"It is tempting to look for a completely fresh approach to transport planning, but this path is rejected. In (my) view, transport planning is basically on the right path and does not need to be radically changed. One difficulty is that quite small technical errors, or faulty assumptions, can lead to disastrous results. Rather than abandon the whole approach, more care and experience are needed in planning the study process and the structure of the models to be used".

Thomson (1983) argues for a more and careful planning. He distinguishes between directional plan that gives a general outline for transportation 20-25 years hence, and design plan that consists of a specific list of projects sufficiently detailed for the inclusion in small term programs. He sees the failures of past attempts as one of confusing between the two kinds of planning by policy makers.

In the recent past, balancers have gained considerable ground within the paradigm. Proponents of this view argue for a more wider mix of transportation modes, particularly the mechanized variety. Owens (1978) identified the increasing use of jitneys, jeepneys, etc., in third world cities as the trend that needs to be fostered by planners. Roschlau (1981) advocates the use of peseros (fixed-route shared Taxi usually with a flat fare) for Mexico City and other middle income third world cities. It is notable that most "balancers" argue for a greater mix of mechanically powered vehicles than all modes of transit. Their grouse is usually against private automobiles.

As a response to the ecological concerns of the use of combustion engines, some within the orthodox paradigm are turning more to the basic needs approach. This is particularly visible in all activities that require fossil fuel. The concept. is to use energy more frugally, for it is argued that such practice is not only ecologically sound, but also economically most viable. Amory Lovins (1991) best summarizes this view, although he speaks from the broader concerns of energy use in general and not transportation particularly.
"The energy problem has already been solved by new technologies-primarily for more efficient end-use, secondarily for more efficient conversion and sustainable supply ... energy need not constrain global development", (pp 117-142).

This approach could also be termed as an "ecodevelopment" approach; more environmentally benign solutions are its mainstay.

\begin{abstract}
"No sensible country would imitate Los Angeles' car dependence or its freeway system, together with their costs, fuelintensity, and smog; instead, it would encourage people to live near where they want to be, work nearer home, telecommute more, and use sophisticated public transport" (p 139).
\end{abstract}

Another stream of thought within the orthodox paradigm concerns itself with the technique of providing transportation for a "greater mass of people", with implicit ignorance about the social, economical and environmental (particularly nonphysical) costs of their policies. These include Rallis (1988), who advocates various modes of transportation on the basis of city density (from buses for Singapore to helicopters for Los Angeles), and Pederson (1980) who bases his analysis on land use patterns and city form.

What can one stay of the Orthodox paradigm, other than that it is insensitive to the problem of movement because of its private-bias? This is primarily seen by the increasing use of automobile (auto $=$ independent, mobile), but also in the "pedestrianization" efforts in cities in the developed world. Lofland (1989: 22) listed some of these attempts: Covent Gardens and Ghiradelli Square in London, New York's Times Square where hotel lobbies ("public" realm) are in the second and third floors, Gallerias sprouting up in every major American city, Shopping malls, Festival markets, Underground pedestrian streets of North America, etc. As Lofland says these are purportedly public spaces that are only marginally public.

There are valuable points made within the paradigm of late, particularly those proponents of an "ecodevelopment" approach. The question however is, to what extent the notion of ecodevelopment (with its "sophisticated public transport", for example) is applicable to third world cities today?

\section{Third World Urban Transportation in the Political Economy Paradigm of Under Development}

Attempts by the radical political economy paradigm is even more disastrous. While the common weakness of viewing transportation as an economic 
activity still remain (Transportation $=$ moving $X$ number of people from point $A$ to point $B$ ) the "solutions" have been two-fold: trustbusters, and transit technicians. (Taebel and Cornehls, 1977: 4) The former is more a reaction against orthodox paradigm (a distaste for private transit) than a solution. The latter emphasize the use of mass transit (buses and jeepneys, in the case of the third world). While the level of pollution emanating from the instruments of mass transit is less per capita (since they carry more people per trip) there are serious problems in using them in third world cities. These include, a heavy initial capital outlay that is beyond the reach of many third world governments, need for imported and therefore hard-currency based spares, an increasing contribution to congestion (see, Wright [1992] for example), a callous disregard for passenger safety and convenience, extremely rigid schedules not facilitating personal mobility but only the institutional need for "providing transport," etc.

As can be expected, discussions on urban transportation within the political economy paradigm is dominated by structuralists who argue for macrolevel changes as pre-conditions for lasting solutions. Arguing from a broad global energy point of view, Pachauri (1985) put forward a three pronged approach: greater energy-efficiency, more investment in third world energy needs, and the creation of a new international economic order.

But the bulk of the discussion on urban transportation within the paradigm tend to revolve around one "solution": greater role for public transportation. Taebel and Cornehls (1977) who wrote an analysis on the political economy of urban transportation, too, felt compelled to conclude advocating public transportation. Their argument for public transportation is three-fold: mass transit leads urban development rather than follows it (as automobiles often do), it is environmentally benign, and it democratizes urban transportation.

"If democracy means something more than a mere set of legal rights, if it means that all citizens will be guaranteed equal opportunities and access to the vast array of activities in the city, then mass transit can well serve to democratize ... cities" ( $p$ 156).

It is argued here that it is precisely for this reason, to "democratize" transportation, that human-powered transit should be promoted by urban design. For, as Illich (1974) says, the only equalizing factor is human metabolism. The true difference between the proponents of privatized auto transport and mass transport is the mode, and not a shift in attitudes. Both advocate more of the same, mechanized transport which in the end, tends to discriminate against the poor.
Although a typical third world city relies almost entirely on public transportation, it is clear that its transportation ills have not diminished in any real sense. Most third world cities are still congested, air pollution rates are actually higher than the first world cities, people are increasingly forced to follow schedules and not the dictates of their personal needs, pedestrian safety is worse in these cities (as evidenced by the number of traffic accidents per vehicle), and share of transportation cost in personal budget is still unbearable for most people.

\subsection{Strategies For Sustainable and Equitable Urban Transportation}

It is clear that existing approaches to urban traffic problems are neither equitable nor sustainable in the long run. This seems to be the case in both dominant economic paradigms as well as in rich /poor countries. What strategies can planners and urban designers advocate to reduce these imbalances?

Praxis in this matter does not have a long history. As such, only tentative suggestions can be made at this point. The fifteen or so years of experience from western European cities in traffic control for greater sustainability seems to offer some lessons. Three broad strategies can be gleaned from relevant literature:

\section{Cap on Per Capita Energy Use \\ 2. Amendments to Zoning Laws \\ 3. Trip Reduction Through Urban Form.}

\subsection{Cap on Per Capita Energy Use}

As mentioned before, equity issues in urban transportation are best addressed when both mechanized and non-mechanized travellers have comparable access to urban activities and facilities. As Illich (1974) pointed out equity increases with energy use only up to a point, beyond which greater energy use leads to greater and greater inequity.

Energy used in urban traffic correlates well with speed. As such, a cap on energy use can be translated into a policy of speed limits. There are two kind of urban street speed limits now emerging: "Traffic Calming" and the Dutch experience of "Woonerr".

\subsubsection{Traffic Calming}

Techniques for traffic calming originated in central Europe in the wake of increasing pedestrian movement in city centers (Hass-Klau, et al., 1992). Traffic conditions in residential neighborhoods, and stronger local governments disstaisfied with the status quo also contributed to their increasing use. Several techniques can be classified as useful in reducing speeds: Round \& Flat-top road humps, 


\section{Measures to be used between junctions}

These are mainly speed reducing measurers, which could be combined with vertical elements, such as trees, bollards or lamp-posts to emphasize the actual site and to improve the street environment.

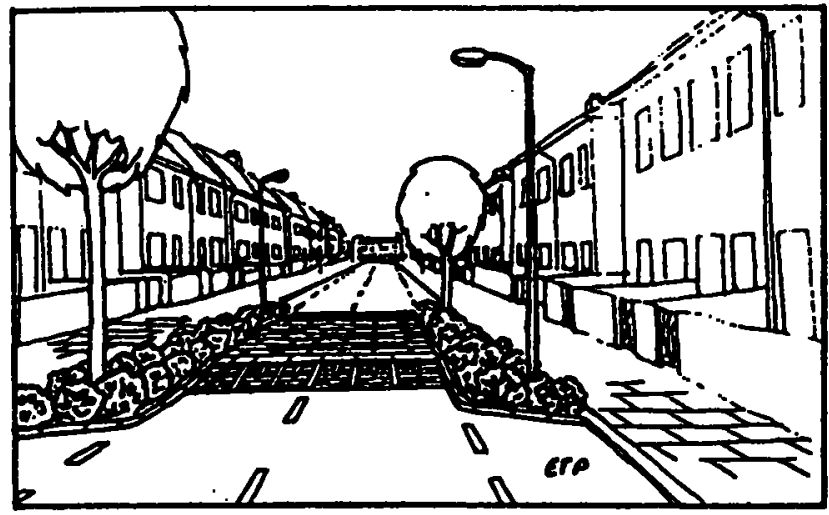

Top $\quad: \quad$ : round-top road hump.

Above left : flat-top road hump.

Above right : speed cushions.

Below left : road depression.

Below right : raised plateau
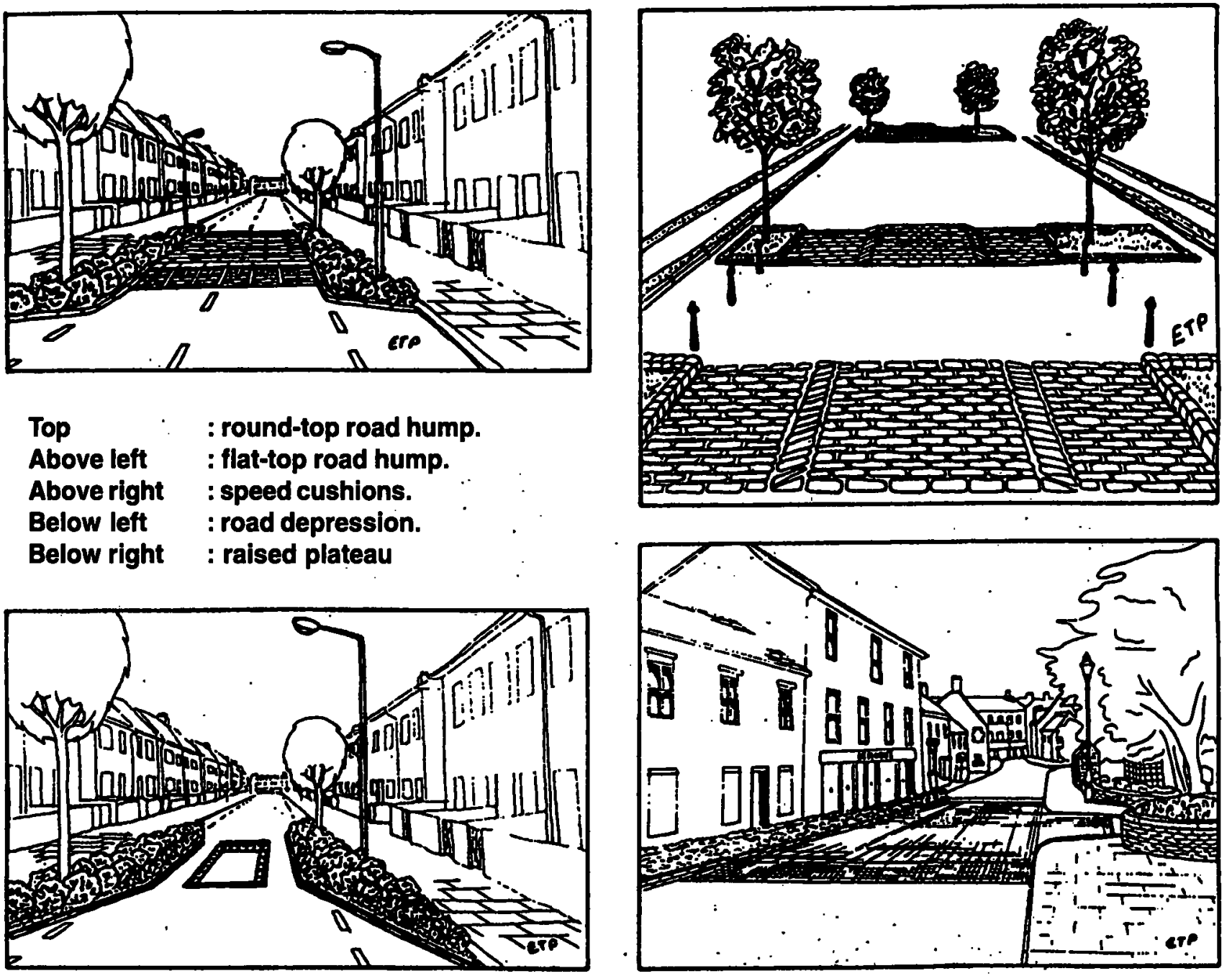

Figure 1: Traffic calming techniquies $-i$

Source: Haas-Klau et al., 1992:5 

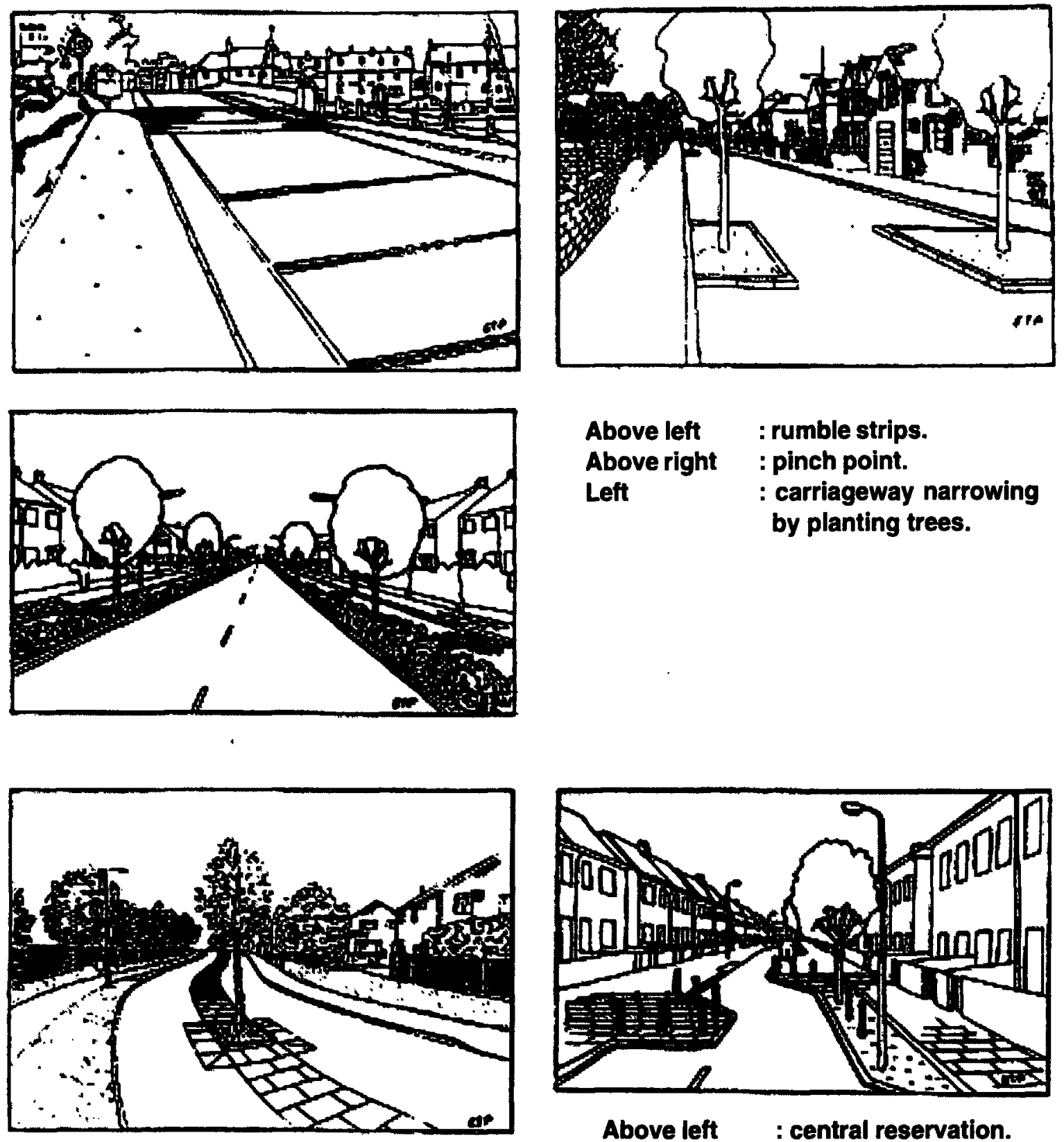

$$
\begin{array}{ll}
\text { Above left } & \text { : central reservation. } \\
\text { Above right } & \text { : chicane. } \\
\text { Below left } & \text { : side strips } \\
\text { Below right } & \text { : traffic island. }
\end{array}
$$
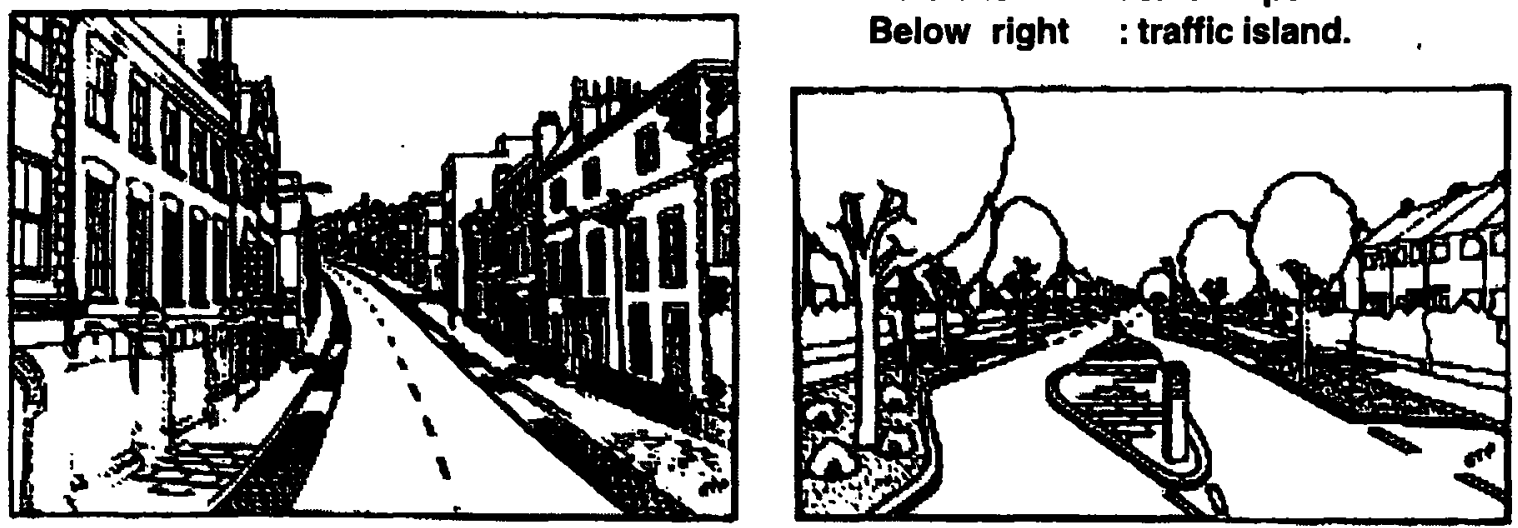

Figure 2: Traffic calming techniques - II

Source: Haas-Klau et al., 1992:5 
speed cushions, road depressions, raised plateau, rumble strips, pinch point, central reservations, chicane, traffic islands, etc. (Figures 1 and 2).

\subsection{2 "Woonerf"}

Literally translated as "residential backyards," this Dutch concept was introduced by planners in Delft in late 60s. By 1976 the program was so successful as to be awarded legal status in the Netherlands (HassKlau, 1992).

A "woonerf" is a no-through-traffic street where cars and other motor vehicles enter on low priority. Parking is permitted, but driving in these streets is made difficult by the winding carriageways, obstructions deliberately caused by pedestrian right-of-ways and parking. Such a traffic calming strategy leads to more

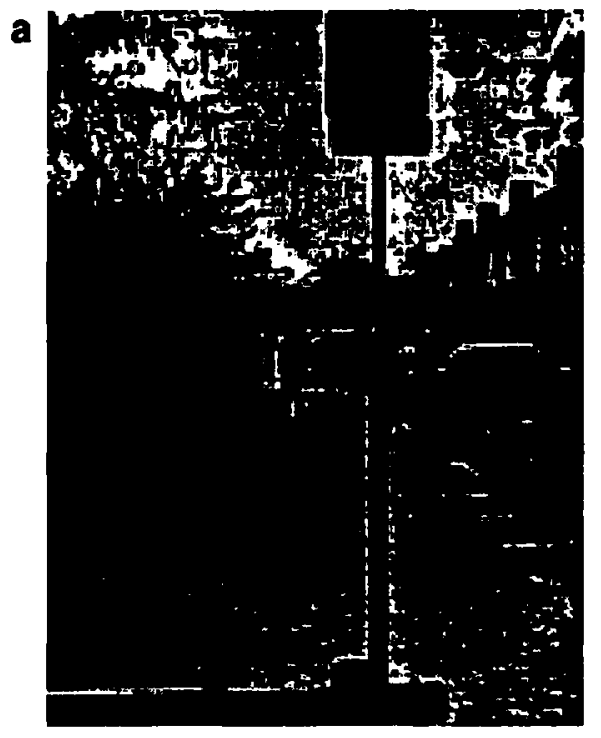
(a) The Dutch Woonerf. Designed as a multi-functional street, it is a social place for games, meetings, growing flowers and vegetables. Cars enter on sufferance

(b) A residential street in Toronto. Here common usage otten supercedes planning doctrine

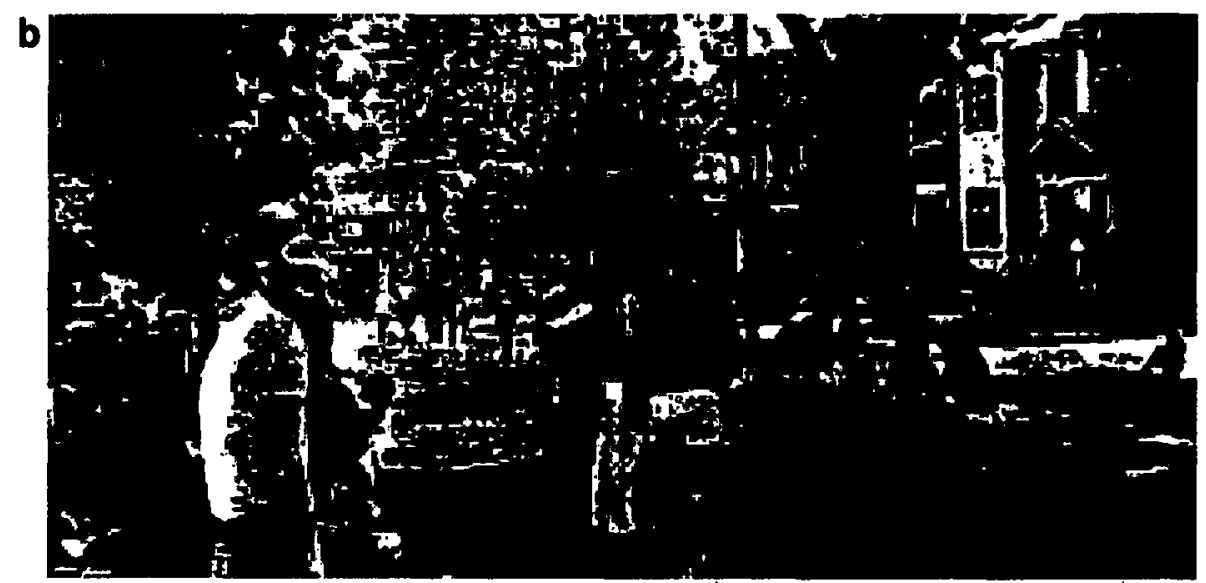

Open space study of residential areas, LeBreton Flats, Ottawa Canada (from Hough Stansbury \& Associates) The analysis of space in a typical mediumdensity residential area shows how much space is officially delegated to cars. People however, don't recognize demarcations of space in such inner-city areas where planning gives way to common usage

\begin{tabular}{|c|c|c|}
\hline \multirow{2}{*}{\multicolumn{3}{|c|}{$\begin{array}{l}\text { Space allocation in residential block } \\
\text { (Delhousie neighborhood, Ottawa) } \\
\%\end{array}$}} \\
\hline Housing 30 & & \\
\hline Backlots & 23 & $\begin{array}{l}\text { No community } \\
\text { recreational } \\
\text { activities }\end{array}$ \\
\hline
\end{tabular}

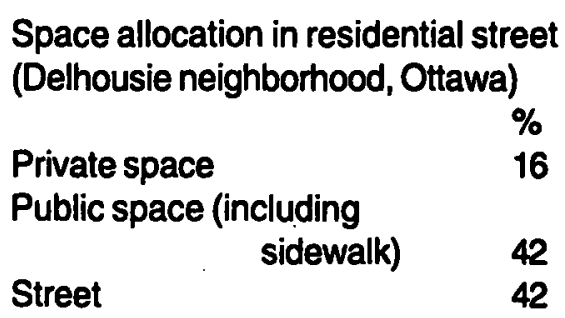

Front gardens 14

Sidewalks 6

Street $\quad 19$

Driveways 8
Highly active areas (total 39\%)

Figure 3: Typical Dutch "Woonerf"

Source: Hough, 1984 
presence of pedestrians and all associated urban activities (Figure 3).

In addition to traffic improvements, "woonerven" have lead to the creation of more open spaces and allowed nature to take hold of city streets.

\subsection{Traffic seperation}

The road network in urban areas is already impressive. Even in a heavily congested city like
Colombo, transportation makes up to $18 \%$ of the land use (Colombo Development Plan, 1985). The reason for transport ills in Colombo is not so much a problem of low space allocation for transportation but an irrational use of the existing allocation.

Even a low profile traffic study would reveal the major arteries of cities. The planning implication of such a revelation is how to convert them in such ways that are profitable to greater number of people. Correa's (1989) proposal for traffic seperation in New Bombay

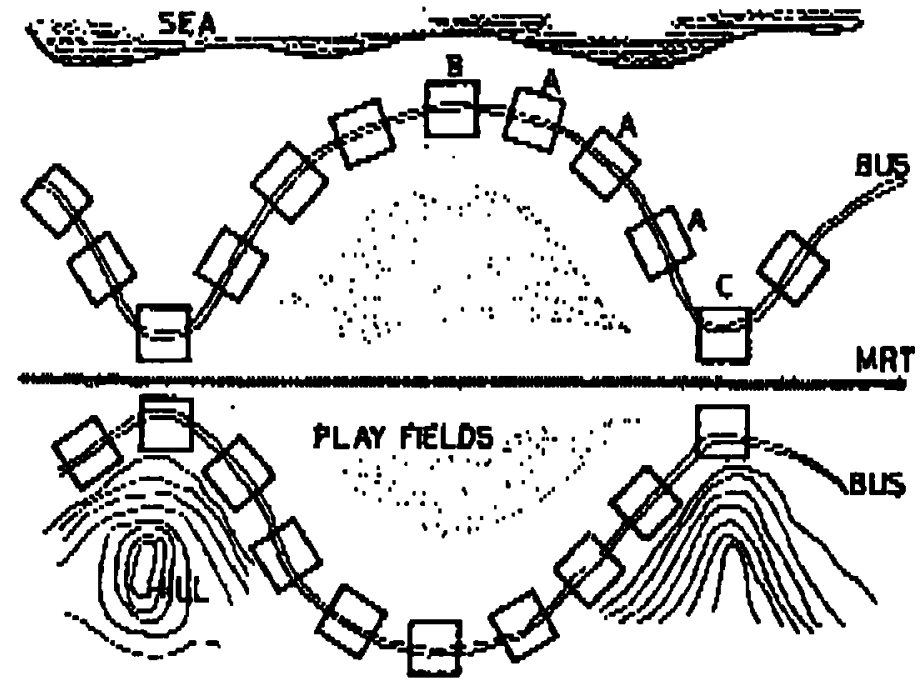

The diagram above shows the proposed system on a typical portion of the New Bombay site (which runs between hills \& water).

In future, in case densities and traffic grow beyond expectation, an additional primary MRT can be installed. This upgrades the importance of some type A sectors (which now provide an opportunity for locating new social infrastructure and other facilities for the additional population). Human settlements have always tended to locate at transport junctions, on a scale directly proportional to the importance of the junction. At the major nodal points, higher densities can be allowed to develop for specialised functions, such as offices, shopping and luxury apartments. Thus a natural hierarchy of nodal points can develop, culminating in the city centre:

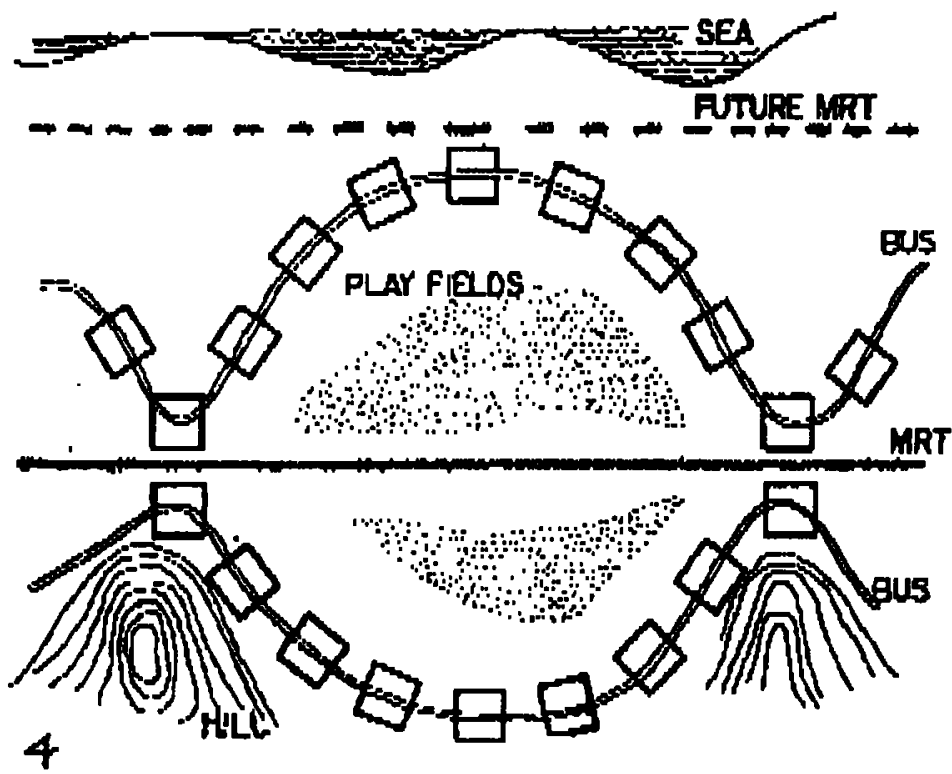

Figure 4: A proposal for traffic separation In Bombay

Source: Correa, 1989 
(Figure 4) may offer some clues to the rational use of existing resources.

\subsection{Amendments to Urban Zoning Laws}

Cities have long encouraged strictly seperated activity zones that have much more to do with $19^{\text {th }}$ Century middle-class fears than rational urban planning needs. Single-zone planning concepts have led to strict activity seperations which can then be serviced only by faster modes of transport.

It is therefore suggested that multi-zone planning be promoted as a more rational approach to reducing urban transportation needs. As Correa (1989) points out, the primary goal in urban transportation should not be how to provide faster transport but how to reduce trips in the first place.

\subsection{Trip Reduction Through Urban Form}

Current urban built densities are typically too low to sustain equitable and clean transport modes like walking and cycling. March and Martin (1961) have long shown that this need not be so. They proved that even a supposedly dense city like New York could be built to its present built density, using buildings no taller than $\mathbf{8}$ stories, if only traffic paths could be re-arranged. The success of equitable modes of transport is contingent upon urban population density. Thus efforts should be made to devise high-density, yet low-rise urban built forms that enable a large enough catchment population to live closer to major traffic centers.

\subsection{Conclusion}

The inequity and un-sustainability of urban transport choices made in both dominant economic paradigms stems from over-dependence on mechanized modes of transport. This paper attempted to show that the demands created by such modes (requirement for large parcels of land, low density population, etc.) are ultimately not sustainable, no matter what mecahnized mode is selected.

Furthermore, the growing number of mega-cities of the world now pose urban population densities unimaginable until recently. For example, New York's current population density is less than 12,000 persons / km², but third world cities like Colombo, Metro Manila and Rio de Janeiro boast population densities in the range of $40,000-50,000$ persons / $\mathrm{km}^{2}$, There is neither land nor monetary resources available in these cities to provide indivual mechanized transport for all the urban dwellers.

It is therefore necessary to look for alternative means of moving urban dwellers. Modes that enable human metabolism to be fully used (Walking, cycling, etc.) and urban design strategies that enable humanpowered modes to compete equitably with mechanized modes offer some possibility of bringing equity to urban transport. They are also more sustainable in the long run. Urban planning and design have important roles to play in bringing about such changes to our cities.

In many cases, what is possible is often determined by what was already experienced as successful. As such, even small attempts in implementing the abovementioned strategies at local and neighbourhood scales can be effective tools in informing the public as to what "real" urban transport choices exist.

\section{References}

Colombo Development Plan, (1999). Battaramulla, Sri Lanka; Urban Development Authority.

Correa, C., (1989). The New Landscape;

Urbanization in the Third World, London: Butterworth.

Erley, D. \& D. Mossena, (1980). Energy Conserving Development Regulation: Current Practice, Planning Advisony Report No. 352, Chicago: American Planning Association.

French, H.F., (1990). Cleaning the Air: A Global Agenda, Worldwatch Institute Paper No. 94, Washington, D.C.: Worldwatch Institute.

Gibbons, S., (1990). "Mixed land-use and multimodal transport: the Kanpur planning environment," (quoted by Wright, 1992, op. cit.).

Hass-Klau, C. et al., (eds.), (1992). Civilized Streets: A Guide to Traffic Calming, Brighton, U.K.: Environmental \& Transport Planning Dept.

Hough, M., (1984). City Form \& Natural Processes, New York: Van Nostrand Reinhold.

Illich, I., (1974). Energy \& Equity, New York: Harper \& Row.

Lofland, L.H., (1989). "The morality of urban public life: the emergence and continuation of a debate," Places, 6(1): 18-23.

Lovins, A.B., (1991). "Energy, people and industrialization," in, Trudeau, Pierre Elliot, (ed.), Energy for a Habitable World: A Call for Action, New York: Crane Russak. 
Lowe, M.D., (1994). "Reinventing transport," in, Brown, L., et al., (eds.), State of the World 1994, New York: Norton, pp. 81-98.

Manning, I., (1984). Beyond walking distance: the gains from speed in Australian urban travel, Canberra, Australia: Australian National University, Urban Research Unit.

March, L. \& L. Martin, (1961). Urban Space \& Structure, Cambridge: Cambridge University Press.

Morris, J.M., (1981). "Urban public transport," in, Troy, P.N., (ed.), Equity in the City, Sydney: George Allen \& Unwin, pp. 21 - 49.

Newman, P.W.G. \& J.R. Kenworthy, (1988). "The transport energy trade-off: fuel efficient traffic versus fuel-efficient cities," Transportation Research, Part A, 22A (May 1988): 163-174.

Owens,W., (1978). Strategies for Mobility, Washington, D.C.: Brookings Institute.

Pachauri, R.K., (1985). The Political Economy of Global Energy. Baltimore: Johns Hopkins.

Pederson, E. O., (1980). Transportation in Cities. New York: Pergamon Press.

Rallis, T., (1988). City Transport in Developed and Developing Countries. New York: St. Martin's Press.
Roschlau, M.W., (1981). Urban Transportation in Developing Countries: the Peseros of Mexico City, Vancouver, B.C.: Center for Transportation Studies, University of British Columbia.

Salihi, J.T., (1973). "Energy requirements for electric cars and their impact on electric power generation and distribution systems," IEEE Transactions, 1A-9 (5): 516-533.

Southeast Michigan Council of Governments (SEMCOG), (1991). Regional Development Initiative, Briefing paper No. 3, Detoit: SEMCOG (unpublished).

Taebel, J. M. \& J. V. Cornehls, (1977). The Political Economy of Urban Transportation Port Washington, N.Y.: Kennikat Press.

Thomson, J. M. , (1983). Towards Better Urban Transport Planning in Developing Countries, World Bank Staff Working Papers, No. 600, Washington, D.C.: World Bank.

Wijemanne, E.N., (1989). Energy Pricing Options for Sri Lanka, New Delhi: International Labor Organization / Asian Regional Team for Employment Promotion.

Wright, C.L., (1992). Fast wheels, Slow Traffic,: Urban Transportation Choices, Philadelphia: Temple University Press. 